\title{
INTERAÇÃO E CONFLITO NO DISCURSO ORAL CULTO
}

Zilda Gaspar Oliveira de Aquino*

Este trabalho tem como proposta examinar a interação nos textos de entrevistas com falantes cultos, atentando-se para a organização desse discurso no momento em que ocorrem conflitos. Para tanto, observamos o evento discursivo como um conjunto de atividades responsáveis pela construção textual, buscando detectar traços significativos de conflito na conversação. Entendemos que a realização dessas atividades resulta de diferentes fatores organizados por estratégias selecionadas e acionadas pelos participantes durante a situação interacional.

Utilizamos os pressupostos teóricos da Sociolingüística Interacional, direcionando nossa atenção aos trabalhos de Goodwin e Goodwin (1992), para quem a análise da participação em atividades permite dizer que os falantes não estão simplesmente envolvidos num contexto, mas o constroem ativamente. Nessa perspectiva, a linguagem é vista como um modo de interação que ao mesmo tempo modela, expande e muda o contexto numa complexa articulação colaborativa na qual os participantes estão envolvidos, especialmente quando ocorre conflito.

O falante tem condições de conduzir seu discurso na direção que melhor convém a seus propósitos. Por essa razão, a estrutura da conversação faz com que os falantes detectem o encaminhamento em termos de compreensão do texto que estão formulando, bem como observem o sentido apreendido por seu interlocutor.

Examinamos as estratégias inclusas no texto e que trabalham como pistas para facilitar a construção do significado, já que partimos da consideração de que a estrutu-

- Faculdades Oswaldo Cruz, São Paulo. 
ra da conversação providencia os mecanismos pelos quais os falantes podem constatar a compreensão do discurso que estão produzindo.

O corpus utilizado na pesquisa engloba transcrições de programas de entrevistas transmitidos pela televisão dos quais participam personalidades da política brasileira. No estudo ora apresentado, tomamos a transcrição do programa Roda Viva, transmitido pela TV Cultura de São Paulo, em que é entrevistado Ciro Gomes, então Ministro da Fazenda, na fase em que era implantado o Plano Real no Brasil e Fernando Henrique estava prestes a se tornar Presidente. O Plano precisava dar certo e a figura séria e forte de Ciro concorria para essa consecução. Durante a entrevista, o convidado precisava estar atento para que nada escapasse e que pudesse ser prejudicial, ou que não contribuísse para o alcance desse objetivo.

Vários jornalistas, representantes de grandes empresas jornalísticas de São Paulo e do Rio de Janeiro, compunham o rol dos entrevistadores, que tinham como condutor geral Heródoto Barbero.

Da mesma forma que no Exórdio, utilizado na Retórica Clássica, a abertura do programa anuncia o entrevistado, delineando-o a partir de seu cargo, suas atividades políticas, sua personalidade. É assim que Ciro Gomes (L2) é apresentado como um ministro jovem, ágil e o mediador (L1) cria um contexto em que se projeta uma imagem de força e agressividade ao estabelecer uma comparação entre Ciro e um veículo forte, preparado para enfrentar adversidades:

L1 a vida corre rápida para Ciro Gomes e apesar da velocidade... se o ministro fosse comparado hoje a um veículo.. a imagem mais apropriada seria não a de um fórmula um... mas de um trator

L1 o ministro vai precisar desta energia... nos sessenta dias que ainda terá no seu posto... para enfrentar... por exemplo... as críticas que são feitas às medidas de restrição ao consumo que acabam de ser adotadas

Acresce a essa imagem a de um ministro que tem por característica formular enunciados a partir de uma seleção lexical informal e, muitas vezes, grosseira. O entrevistador, utilizando-se de um contorno prosódico específico, enfatiza determina- 
Linha d'Água, n. especial, p. 11-23, jan. 2000.

dos elementos lingüísticos selecionados (tem NOjo dos políticos) e indica o contexto anterior em que esse enunciado ocorreu (PUblicamente):

\section{L1 já declarou PUblicamente ter NOjo dos políticos (lin.15)}

Há momentos em que o entrevistador (Heródoto) recusa-se a repetir enunciados do entrevistado do modo como foram formulados por este, mas parafraseia e avisa (como destacamos no texto) que "a expressão não foi bem essa". Ao interagir dessa forma, Heródoto cria um contexto em que se coloca de modo superior ao entrevistado Ciro Gomes e este se fixa como alguém rude, grosseiro, duro:

L1 afirmou que daria quatro pancadas... aliás a expressão não foi bem esta... para derrubar a inflação... e ainda classificou de Canalhice a atitude de empresários que cobram ágios e aumentam preços

O ministro, como participante atento, aproveita a primeira oportunidade para reverter a idéia de força a favor de sua imagem; assim, coloca-se como alguém tão forte que se considera capaz de curar algo dificilmente curável, dado o tempo da doença:

L2 esta é a melhor oportunidade que nós temos de curar o câncer da inflação de nossa convivência social

$\mathrm{Na}$ verdade, durante toda a entrevista Ciro se mostra muito atento às estratégias utilizadas pelos entrevistadores, exigindo deles precisão na formulação das seqüências. Assim, quando se modela um contexto em que a informação não corresponde à verdade, temos pontos de conflito e Ciro interage de modo a fazer valer sua verdade, como se observa no segmento em que L4 (jornalista) emprega os termos "abafar" e "crescimento", mas Ciro (L2) interage de modo a corrigir seu interlocutor, indicando outros elementos lingüísticos mais precisos:

L4 - ministro... a semana passada... as medidas que o senhor anunciou na semana passada... são medidas que podem ser até consideradas... TECnicamente 
corretas... quando se quer:: abafar uma inflação que tendia a crescer por falta... de oferta de produtos

L2 não abafar não... não permitir que aconteça inflação [

L4 perfeito

L2 - não perfeito não é ... a diferença é essencial<smiles>[TlH]</smiles>

L4 não eu sei...

L2 - porque abafar parece

$$
\text { [ }
$$

L4 - impedir o crescimento...

L2 - que a coisa existe e você põe o congelamento em cima/

L4 - impedir o crescimento de uma

L2 - então vamos esclarecer bem por que(...)

L4 - impedir o crescimento de uma inflação e::

L2 -

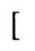

impedir o nascimento da inflação

(lin.820-840)

A perspectiva de que existem pontos de vista diferentes entre os interlocutores é indicativa da necessidade de se negociar, de interagir produzindo uma realidade nova ou transformando a realidade apresentada pelo interlocutor para conseguir a adesão dos outros participantes (o auditório). A interação deve ser carregada de eficácia, ainda que provoque, incite, predisponha o interlocutor também a agir, mas numa direção determinada, como o faz o ministro no trecho a seguir em que anuncia a impossibilidade de continuar a discussão nos termos propostos pelo interlocutor L6 (jornalista):

L6 o que me preocupa é digamos é a palavra do ministro que de repente é:: fica subs:: não digo suspeita... mas o pessoal começa a desconfiAR... se o ministro vai à televisão e começa dizer... olha... adie tuas compras 
L2 não permanece avisando a mesma coisa... não tem que ter razão pra se preocupar

[

L[] - $\quad$ sim mas de repente... a:: essas decisões todas foram tomadas para iniBIR o consumo... então Essas pessoas ... eu até sinto já ouvi VÁrias pessoas me falando nisso... se sentiram é::: passadas pra trás... lesadas<smiles>[Tl]</smiles>

L2- não é verdade... não... não é verdade...

L6- enganadas porque de repente queriam comprar e não compraram

L2- não é verdade... não... não é verdade... não... não é verdade

L6- $\quad$ enganadas porque de repente queriam comprar e não compraram [

L2- $\quad$ não é verdade... não... não é verdade... não... não é verdade

L6 - porque o ministro pediu para adiar a compra e de repente acontece isso

L2 - $\quad$ olha é muito dificil a gente participar de uma discussão dessa natureza... porque as pessoas que tão nos assistindo tão aífora e podem ser consultadas como EU faço sistematicamente( )

A falta de acordo faz com que surjam as considerações, o que leva à discussão e origina a necessidade de se pensar melhor na negociação. São importantes aqui as diferentes estratégias de negociação por permitirem que os participantes cheguem a acordos, atinjam o fim a que se propuseram durante a interação.

É consensual a indicação de que interagimos para conseguir adesão do interlocutor às nossas crenças e necessidades; entretanto, por inúmeras razões, não são raras as vezes em que tal fato se torna difícil, ocorrendo momentos em que não 
conseguimos os melhores resultados numa interação e esse é o ambiente propício para se instaurar o conflito.

Ciro está sempre atento para não cair nas armadilhas que os entrevistadores possam criar e que atinjam sua face positiva (Goffman, 1987), mudando ou criando uma imagem pública que não é a que ele quer; nesses instantes, o ministro procede de mais de uma forma: com paciência, mas contestando; com indignação; com negativas peremptórias.

A postura do ministro é a de quem controla a situação de modo a não deixar escapar nada que lhe desagrade. Assim, no momento em que L7 (jornalista) faz-lhe algumas acusações, ele reage:

L7 - ministro... neste programa até agora o senhor usou... as seguintes expressões alGUmas das que eu anotei aqui... a respeito dos especuladores... ((mudando o tom de voz e o ritmo)) nojentos... canalhas... safados...( )

L2 - espera um pouquinho eu não falei nem nojento nem canalha... isso foi o senhor que falou

L7 continua afirmando e, com um sorriso, tenta demonstrar que entra em acordo:

L7 - o senhor falou canalha ((rindo))... mas tudo bem... de qualquer maneira... (lin.1524-5)

Entretanto, L2 (Ciro) continua a interagir, opondo-se:

L2 - não é possível pois... na verdade... o senhor está querendo desqualificar minha opinião

L7 - não não pera aí não é nada disso...

L2 o senhor não está preocupado com as minhas palavras está preocupado em desqualificar minha opinião

L7 - não não... MUIto ao contrário... eu queria/ 
L2 - mas o senhor não pode dizer que eu falei canalha porque eu não falei

L7 - o senhor mencionou aqui/

L2 - não eu não falei não... eu expliquei pra ele eu expliquei pra ele em que contexto eu tinha usado

[

L7 - $\quad$ quando explicava o episódio dos... dos otários

[

L2 - a expressão canalhice

L7 - $\quad \operatorname{sim} \operatorname{sim}$

L2 - daí ao senhor dizer que eu usei aqui em relação aos

L[ ] - $\quad$ especuladores a palavra canalha...

(lin.1526-48)

Num trecho em que se observa negociação e ocorrência de muitas sobreposições, L7 pede desculpas e parece novamente aceitar um acordo, mas continua interagindo de modo a afrontar seu interlocutor:

L7 - tudo bem o senhor me desculpe

L2 - o senhor desculpa eu também por

L7 - $\quad$ sim

L2 - que eu estou meio comovido com isso... as pessoas abandonaram minha opinião...

[

L7 - perfeito

L2 - abandonam minhas providências... e querem desqualificar minha posição... e eu conheço isso ó:... ((estala os dedos)) de longa data ficando numa palavra assim... parece que o cara é um destemperado 
L7 - não não... muito pelo contrário... não me parece não... isso não teve essa pressão

L2 - que não pensa no que está falando...

L7 -

só repito pro senhor ... um cidadão dizer que vai aumentar preço porque passou a eleição pra mim é uma canalhice... foi nesta hora e nestc contexto que

\section{L7 - perfeito}

L2 - eu usei e usarei até a morte

L7 - $\quad$ perfeito

L2 - pedindo desculpas por quem se choca com isso

L7 - não não eu não me choco

L2 - mas por favor não desqualifique minha opinião

L7 - mas eu gostaria... de aproveitar a oportunidade... e lhe pedir... os nomes dessas pessoas... quais são... que segmentos da

É preciso estar atento, pois o inimigo pode contra-atacar. É assim que L2 (ministro) reage, avalia, entende que L7 (entrevistador) quer mesmo é criar conflito e pede para ser mudado o entrevistador - comandando a entrevista, alterando os papéis -, pois o que é inadequado ou a quem é desequilibrado não se deve atender: 
L7 sociedade... quais são essas pessoas...

L2 - eu acho isso uma provocação e passo à pergunta seguinte... quem é? ((risos do Casado))

A análise de como se organiza a interação nos textos de entrevistas requer como preocupação imprescindível a consideração da terceira-parte. Esta determina a condução do discurso seja por parte do entrevistado ou do entrevistador. É preciso ressaltar que o auditório pode não ser o mesmo do princípio ao fim de um discurso e os participantes precisam estar atentos para este fato. $\mathrm{O}$ auditório vai sofrendo transformações de acordo com a habilidade do entrevistador e é preciso, portanto, ponderar o fato de que embora haja um roteiro prévio, dependendo de qual sejam as respostas às questões formuladas, o entrevistador precisa perceber a necessidade de um possível reencaminhamento tanto do tópico, como da interação em si.

Erlich (1993) salienta que, quando o tipo de interlocução polêmica ocorre diante de um público (terceira-parte), a intenção imediata de cada interlocutor é a de valorizar sua imagem ou de fazê-la parecer melhor do que a de seu parceiro.

Além disso, é preciso considerar o fato de que, muitas vezes, num discurso, ocultam-se desigualdades, neutralizam-se oposições e que inúmeros recursos podem ser utilizados para tal fim. Nesse sentido, o locutor precisa estar atento às estratégias empregadas tanto por ele quanto pelo interlocutor; já que se podem detectar a presença de certos recursos retóricos, de modalizações, de abrandamentos para a consecução desse empreendimento.

É ilustrativo o segmento do qual participa a entrevistadora L3. Ao ser indicada para iniciar a participação dos entrevistadores, a jornalista formula seu enunciado utilizando-se de uma comparação para dizer o contrário e um questionamento em que se evidencia uma agressividade sutil em relação ao estilo Ciro Gomes, o que é possível de ser observado pela presença de uma pergunta a ela mesma, retórica, com um contorno prosódico denunciador de que uma asserção revestiu-se sob a forma de pergunta, para parecer mais forte:

L3 - (...) a respeito desse seu estilo a:: de trator... será que ele é eficaz?... o ministro da Fazenda do México... Pedro Aspi... no tempo do governo de Sallinas de Gortalli... que promoveu uma estabilização com sucesso... 
costumava ser conhecido pelo fato de Prender oito empresários por semana... e não fazer nenhuma declaração contra eles... a público... o senhor parece que adota a posição contrária...gosta de a::do estilo agressivo... mas eu me pergunto se não é oco esse discurso... se ele realmente leva a alguma coisa

Indicamos Goodwin (1992), para quem é preciso investigar de modo pormenorizado como os participantes exploram dinamicamente a organização seqüencial, a participação nos frameworks e a organização contextual como recursos criativos para a organização das atividades discursivas.

Em seus estudos, o autor aponta para as razões de se indicar a organização seqüencial como um aspecto importante a ser considerado nas situações de conflito, e podemos dizer que ela mesma é responsável, muitas vezes, por instaurar o conflito, dado o efeito que promove. Isto sugere que, nas ações que estão sendo produzidas, os participantes podem estar atentando para as particularidades da atividade em que estão envolvidos ou para o propósito das relações entre eles; assim, a observação da organização seqüencial da fala pode ser indicativa dos propósitos sociais que são negociados por meio dessa organização.

Nos segmentos abaixo indicados, o ministro dá indícios de identificação da atividade que está sendo desenvolvida pelo seu interlocutor, ao elaborar enunciados com comentários indicativos de interpretação a respeito das formulações daquele; são as metamensagens, assim denominadas por Tannen (1987), que podem ser detectadas nos momentos de conflito, funcionam como verdadeiros elementos desencadeadores de conflito e acabam por desarmar um dos interlocutores, revelando que suas intenções foram descobertas.

L2 - o senhor esta desqualificando minha opinião.....

L2 - o senhor está querendo com isso passar uma imagem....

Torna-se necessário observar a importância da adaptação do discurso aos efeitos pretendidos e a tarefa parece não ser de fácil execução, já que uma série de questões precisam ser observadas para que não se instaure um discurso pleno de conflitos. Ciro demonstra estar atento a esta questão quando observa, também por meio de metamensagens, a maneira como acabara de formular um enunciado, seja para des- 
manchar a imagem que se criara desde o início da entrevista, seja para simplesmente ser irônico:

L2 - fui moderado?... não fui?

L2 - fui elegante desta vez?

(lin. 1935)

De um modo geral, as análises pragmáticas têm focalizado a maneira como as ocorrências de fala estão inseridas numa ampla atividade em que os participantes estão envolvidos. Entretanto, muitas das análises (Goodwin, op.cit.) têm procedido à observação das sequiências como se elas estivessem desvinculadas das expectativas dos interlocutores, e estas expectativas, muitas vezes, podem ser identificadas e localizadas em termos da própria formulação dos enunciados desses interlocutores.

À indicação de Goodwin, incluímos a observação não das trocas em si, mas do tópico e seu desenvolvimento, em razão de considerarmos imprescindível apontar para a complexidade do evento discursivo, chegando a evidenciar a que os participantes estão atentos, como eles mudam de enunciado para enunciado, embora seja observado freqüentemente como um comportamento disruptivo, na verdade localiza-se um discurso interligado por meio de um processo de intrincada coordenação entre as partes que estão em oposição.

Entendemos que a conversação comporta, potencialmente, conflito e observamos o texto como um todo, do início ao final de um encontro. Entretanto, tendo em vista o objetivo deste trabalho, destacamos somente partes do texto de entrevistas, tecendo comentários que possam de algum modo resgatar a formulação textual como um todo.

Fisher (1988) também admite que, se tomarmos um trecho isoladamente, pode ser impossível a compreensão do discurso, destacando a necessidade de observação de um contexto amplo'. E se entendemos que todos os elementos presentes num discurso se articulam, interagem, podemos dizer que essa articulação ocorre tanto horizontal (entre os enunciados recém- formulados) como verticalmente (entre os enunciados do próprio locutor e deste com o de seu interlocutor). Tal fato remete à própria organização do discurso, que tem como fio condutor o tópico discursivo.

1 Outros pesquisadores também se pronunciam nesse sentido. Veja-se SCHEGLOFF, E. A. In another context. In: GOODWIN e DURANTI (orgs.), 1990: 191. 
Erlich (1993) afirma que, no discurso polêmico, o objetivo de cada participante é convencer, defender ou impor seu ponto de vista. Assim, as estratégias utilizadas não servem apenas como argumento para indicar que existe um desacordo, mas para mostrar que, ao interagir opondo-se, é possível fazer conhecer ao interlocutor um ponto de vista e, ainda, impor-se.

Torna-se necessário apontar que a noção de estratégia utilizada opõe-se diametralmente àquela de lei, já que não operamos com questões de modelo idealizador que comporte um sistema de regras, mas observamos as regularidades do discurso que se processa a partir de uma rede de estratégias e que são reconstruídas durante a análise da linguagem em contexto.

Cada estratégia tem uma função e um objetivo, independentes do fato de que se consiga ou não o intento proposto. Erlich (1993:45) indica a importância em se observar que:

“... por lo general las estrategias no se presentam explícitamente.

En efecto, el que interviene non dice lo que está tratando de lograr a través de un determinado comportamiento lingüístico."”

Diante de um discurso polêmico é preciso que, de antemão, os participantes do evento se sintam animados a se utilizarem das estratégias discursivas que conhecem/ dominam; que creiam ser possível alcançar seus objetivos. Se o propósito parte de um só dos interlocutores, observa-se que não há oposição e que não se instaura o conflito.

\section{Conclusão}

Em vista do exposto, observamos que não se pode prever o desenvolvimento de uma atividade interacional; conseqüentemente, também não podemos indicar de antemão quais estratégias discursivas serão utilizadas pelos participantes dessa atividade, pois elas dependem da situação de interação e dos participantes da mesma, da relação que estes mantêm, dos conhecimentos de que dispõem.

2 “...de modo geral, as estratégias não se apresentam explicitamente. Na verdade, o que intervém não indica o que está tentando conseguir com aquele determinado comportamento lingüístico." 
Podemos afirmar que as estratégias de negociação são responsáveis pelos ajustes durante o processamento da interação, mesclando-se com outras estratégias (como as argumentativas, por exemplo), para compor o tecido textual.

Especificamente no que concerne ao texto de entrevistas sob análise, do qual participam falantes cultos, detectamos a ocorrência de uma forte tendência a que os participantes utilizem estrategicamente certas atividades, como as de correção, revelando a necessidade de uma reorganização das ações e/ou infrações dos participantes, tendo em vista, especialmente, a presença da audiência.

Desse modo, certos procedimentos estratégicos podem-se instaurar como necessários para a resolução de problemas interacionais, observando-se, inclusive, um dinamismo na atividade discursiva no momento em que ocorrem oposições.

\section{Bibliografia}

AQUINO, Z. G. O. (1997) Conversação e conflito: um estudo das estratégias discursivas em interações polêmicas. Vol I e II. (Tese de Doutoramento). São Paulo: Universidade de São Paulo.

ERLICH, F. D. (1993) La interacción polémica: estudio de las estrategias de oposición en francés. Caracas: Universidad Central de Venezuela.

FISHER, A. (1988) The logical of real arguments. Cambridge: Cambridge University Press.

GOFFMAN, E. (1981) Forms of talk. Philadelphia: University of Pensylvania Press.

GOODWIN, C.; GOODWIN, M. H. (1992) Assesments and the construction of context. In: DURANTI, A.; GOODWIN, C. (eds.) Rethinking context. Language as an interactive phenomenon. Studies in the social and cultural foundations of language n.11. Cambridge: Cambridge University Press. p. 147-190.

TANNEN, D.; WALLAT, C. (1987) Interactive frames and knowledge schemas in interaction: examples from a medical examination/interview. Social Psychology Quaterly 50, n. 2. 